Ezequiel Meretta, P., \& Rezende Ventura, C.R. (2021).

Locomotion and righting behavior of sea stars:

a study case on the bat star Asterina stellifera

(Asterinidae). Revista de Biología Tropical, 69(S1),

501-513. DOI 10.15517/rbt.v69iSuppl.1.46392

DOI 10.15517/rbt.v69iSuppl.1.46392

\title{
Locomotion and righting behavior of sea stars: a study case on the bat star Asterina stellifera (Asterinidae)
}

Pablo E. Meretta ${ }^{1 *}$

Carlos Renato Rezende Ventura ${ }^{2}$

1. Estación Costera J.J. Nágera, Instituto de Investigaciones Marinas y Costeras, Consejo Nacional de Investigaciones Científicas y Técnicas de Argentina-Universidad Nacional de Mar del Plata, Mar del Plata, Buenos Aires, Argentina; pabloemeretta@gmail.com (*Correspondence).

2. Departamento de Invertebrados, Laboratório de Echinodermata, Museu Nacional/Universidade Federal do Rio de Janeiro, Quinta Da Boa Vista S/Nº São Cristóvão, Rio de Janeiro, RJ20940-040, Brasil; ventura@acd.ufrj.br

Received 13-VIII-2020. Corrected 25-IX-2020. Accepted 29-X-2020.

\begin{abstract}
Introduction: The locomotion behavior of an organism involves the integration of aspects like body symmetry, sensory and locomotor systems. Furthermore, various ecological factors seem to be related to locomotion characteristics, such as foraging strategy, migration trends, response to predators and competitors, and environmental stress. Objective: To analyze locomotion and the influence of body symmetry in the crawling and righting movements of the sea star Asterina stellifera. Methods: We carried out laboratory experiments in aquariums in the presence/absence of water current and on a horizontal and vertical surface. Results: The speed is similar to speed in other species of similar size. Both the speed and linearity of displacement were independent of individual body size. A water current leads to faster crawling and straight paths, but there is no rheotaxis: streams do not affect locomotion. Speed and linearity of displacement were independent of individual body size. The displacement pattern described here may be an adaptation of organisms that present dense populations in communities with high prey abundance, as is the case of $A$. stellifera. Conclusions: Like other asteroids, this species did not show an Anterior/Posterior plane of symmetry during locomotion, or righting movement: it does not tend to bilaterality.
\end{abstract}

Key words: crawling; orientation; bilaterality; Asteroidea; rheotaxis; gravitaxis.

Crawling behavior comprises various specific aspects of animals, involving integration of body symmetry, sensory and locomotory systems. Other physical and chemical cues influence the propensity to orient towards or away from a stimulus, e.g. taxis mediated locomotion due to water flow, the presence of attractive or repulsive odorants (Dusenbery, 1992; Wyeth, Woodward, \& Dennis-Willows, 2006).

Locomotion traits of asteroids have called the attention of researchers for a long time.
The reaction of sea stars to a water current is variable: some species show a positive rheotaxis (Castilla 1972; Sloan, 1979, 1980; Sloan \& Northway, 1982; Rochette, Hamel, \& Himmelman, 1994; Dale, 1997; Swenson \& McClintock, 1998), whereas others do not seem to respond to that stimulus (Dale, 1999). The importance of water flow and chemical stimulus as orientation cues is remarkable in many sea star species, but with contradicting results in differentiating the effect of 
each one separately (Sloan \& Campbell, 1982; McClintock \& Lawrence, 1981, 1984; Valentincic, 1983, 1985; Moore \& Lepper, 1997). Consequently, it is not clear whether asteroids have a uniform or aleatory crawling behavior. Furthermore, the effect of gravity on locomotion is not well known. It is interesting to study this locomotion characteristic in species found in environments with high bottom heterogeneity, e.g. rocky boulders.

Several studies have also investigated movements oriented by one body axis in asteroids, i.e. do they move to the right or the left or backward/forward? These studies reached contradictory results: some species show a bilateral plane of symmetry (Cole, 1913; Polls \& Gonor, 1975; Ji, Wu, Zhao, Wang, \& Lv, 2012), but not others (Preyer, 1887; Ohshima, 1940; Montgomery \& Palmer, 2012).

Different ecological aspects of asteroids (i.e. foraging behavior, migration pattern, response to predators and competitors, and environmental stresses) appear to be related to their crawling actions (Feder \& Christensen, 1966; Gaymer \& Himmelman, 2008). Understanding the locomotion pattern (crawling speed, movement direction) would help characterize an organism's different behaviors.

The sea star Asterina stellifera is an omnivorous top predator that actively searches for its prey. This species has a wide variety of prey items, from algae to benthic invertebrates. Asterina stellifera can modify species abundance in the subtidal community of Mar del Plata rocky bottoms. Large fragmented boulders of big rocks and vertical walls of orthoquartzite blocks characterize the sampling area (Genzano, Giberto, \& Bremec, 2011). Therefore, studying this species' locomotion pattern is a first step in understanding its foraging strategy (Meretta, Rubilar, Cledón, \& Ventura, 2014; Meretta, Farias, Cledón, \& Ventura, 2016).

Some basic questions related to sea stars locomotion arise. How do sea stars behave during locomotion? Do sea stars follow a usual locomotion pattern? Do bigger sea stars move faster than smaller ones? How does water flow affect the crawling behavior of sea stars? How does a vertical surface affect its locomotion? Do they behave bilaterally?

We performed an experimental approach under laboratory conditions to investigate physical and biological factors' influence on the locomotion ability and movements' orientation to address these questions. We aimed to (1) describe the effect of the individual's body size (radius and body weight), water current (rheotaxis), and inclination plane (gravitaxis) on the crawling traits of sea stars and, (2) whether their plane of symmetry defines locomotion and up-righting movements.

\section{MATERIALS AND METHODS}

Collection and maintenance of asteroids: Samples of specimens occurred using SCUBA from the port of Mar del Plata, Argentina ( $38^{\circ} 02^{\prime} \mathrm{S} \& 57^{\circ} 31^{\prime} 30^{\prime \prime} \mathrm{W}, 6-8 \mathrm{~m}$ depth). We immediately took the sea stars to the laboratory after collections.

Two-week acclimatization of the individuals took place in 3001 tanks with an open water flow system that pumps seawater directly from the ocean during all experimental time. The aquarium seawater temperature used varied between $18-22^{\circ} \mathrm{C}$. A timer kept the photoperiod at $12 \mathrm{~h}$ light: $12 \mathrm{~h}$ dark. In all tanks, the individuals stayed on the observed field mean density $\left(\approx 12 \mathrm{ind} / \mathrm{m}^{2}\right)$ (Meretta et al., 2016). Asteroids received a continuous food supply similar to those found in the natural environment (Farias, Meretta, \& Cledón, 2012). All experiments occurred with one individual at a time. Furthermore, each individual was used only once and in a single trial and then returned to its environment. After each test, the aquarium was emptied, scrubbed, rinsed, and cleaned with fresh seawater, and refilled to avoid bias from residual chemical cues.

Experimental design: We conducted experiments to describe sea stars' locomotion behavior and the existence of a plane of symmetry during locomotion and up-righting movements. To characterize the locomotion 
behavior, we investigate a rheotaxis response and the occurrence of a gravitaxis behavior.

Rheotaxis response: We carried out experiments on the crawling behavior on a horizontal surface under two water-flow regimes: still water $(\mathrm{N}=120)$ and one-direction flow $(\mathrm{N}$ $=120$ ). A pump provided a continuous flow of filtered seawater across the experimental aquarium through a PVC pipe to simulate and standardize a one-direction water current. Seawater entered the aquarium through the inflow pipe on one wall and drained out back to the sea through openings in an outflow pipe on the opposite wall (Fig. 1). The current was nearly linear across the tank during trials at a velocity of $1.5 \mathrm{~cm} / \mathrm{s}^{-1}$ (observed with methylene blue dye). The current flow used was equivalent to a moderate current speed in the habitat of this species.

Experiments occurred on an aquarium of $80 \times 80 \times 20 \mathrm{~cm}$ with a $2 \times 2 \mathrm{~cm}$ grid marked off (Fig. 1), with the origin $(0,0)$ at the center to monitor the animals' movements. Each sea star started moving from the center of the grid $(0,0$ : initial position, Ip; Fig. 1$)$, referred to by its madreporite position.
Gravitaxis response: A fixed-volume of seawater with no external seawater supply and no flow characterizes the second type of experiment (still water treatment). The substrate was a glass of $80 \times 80 \mathrm{~cm}$ marked with a $2 \times 2 \mathrm{~cm}$ grid, and the water column was about $90 \mathrm{~cm}$. During vertical locomotion trials $(\mathrm{N}=120)$, the substrate was first in a horizontal plane. Immediately, we carefully moved the substrate in a vertical plane, and the animal was allowed to crawl freely. During trials, each sea star placed alone inside the aquaria, started moving freely from the Ip, referred to by the madreporite carefully placed at the origin (Fig. 1).

Crawling experimental measurements: For both experiments mentioned above, we measured the sea stars' wet weight $( \pm 0.1 \mathrm{~g})$ and radius $( \pm 0.1 \mathrm{~mm}$; from the center of the disc to arm tip). Monitoring of each sea star trajectory displacement referred to the madreporite as a fixed point over time. Records of the sea star path occurred, dividing sections per minute of locomotion. We called $T$ (total distance traveled) the sum of all parts covered by an individual during one observation (Fig. 1). We recorded the instantaneous

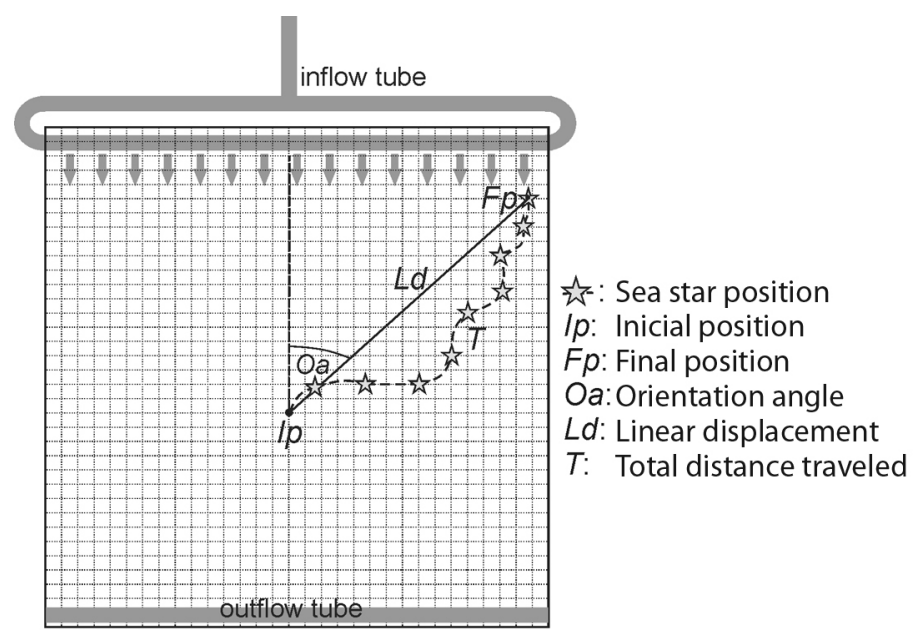

Fig. 1. Diagram of the experimental aquarium $(80 \times 80 \times 20 \mathrm{~cm})$ with a bottom grid of $2 \times 2 \mathrm{~cm}$ squares, showing the tank water flow and the initial $(I p)$ and final position $(F p)$ of the sea star. Grey arrows indicate water direction. Representation of one sea star trajectory, depicting total distance traveled $(T)$ and linear displacement $(L d)$. The sea star orientation angle $(O a)$ represents the angle between $L d$ and water direction. 
crawling velocity over one-minute intervals. According to Montgomery and Palmer (2012) and Montgomery (2014), we calculated the average crawling speed (ACS) from the maximum instantaneous velocities (plateau) at the top of the speed-time curve.

During each trial, we recorded the number of times a sea star changes its crawling direction (DC). The linear displacement between the points that represent the initial and final position ( $I p$ and $F p$, respectively) was called $L d$. Trajectory straightness (linearity, $L$ ) is a dimensionless value, and it means the ratio of $L d$ to $T$, $L=L d / T$ (Fig. 1). The $L$ range is 0 to 1 , where 0 is maximum sinuosity, and 1 is maximum straightness. Classification of linearity levels was as follows: highly directional (higher than 0.7 ), partially directional (from 0.5 to 0.7 ), and non-directional (lower than 0.5) (Ferlin, 1973; Scheibling, 1981).

Since moving in a straight line towards any wall may also produce linearity of 1 , we recorded the orientation angles to distinguish between movements towards each lateral border. We considered the sea star orientation as the angle $(\mathrm{Oa})$ between the straight line at the origin $(0,0)$ and the line representing the trajectory traveled ( $F p$ coordinates, Fig. 1). For horizontal crawling trials, an angle of zero pointed directly to the current water source. We plotted all angular measurements on a $360^{\circ}$ grid and calculated clockwise.

All experiments finished when the sea star reached one of the aquarium walls or after 15 minutes of inactivity. The observation of the madreporite position occurred visually every minute.

Bilateral response: We carried out experiments in aquariums $(40 \times 40 \times 30 \mathrm{~cm})$ with still water to analyze the existence of a bilateral plane of symmetry affecting locomotion and up-righting movements in A. stellifera. For the first experiment, 120 sea stars were randomly oriented relative to the madreporite and placed in the aquaria center. Individuals were left to crawl freely. We recorded the preferred crawling direction as the individual's final arm position relative to the initial orientation. For the second experiment, 100 individuals were turned upside down and allowed to turn back freely to analyze righting movements. We record the arms used during up-righting turning.

We used three different arm-numbering systems to test the existence of a plane of symmetry during both experiments mentioned above (Fig. 2). To this end, the number given to each arm was as follows: (1) sea stars' arms were individually numbered clockwise from the madreporite, (2) the equivalent position of each arm across the madreporite plane of

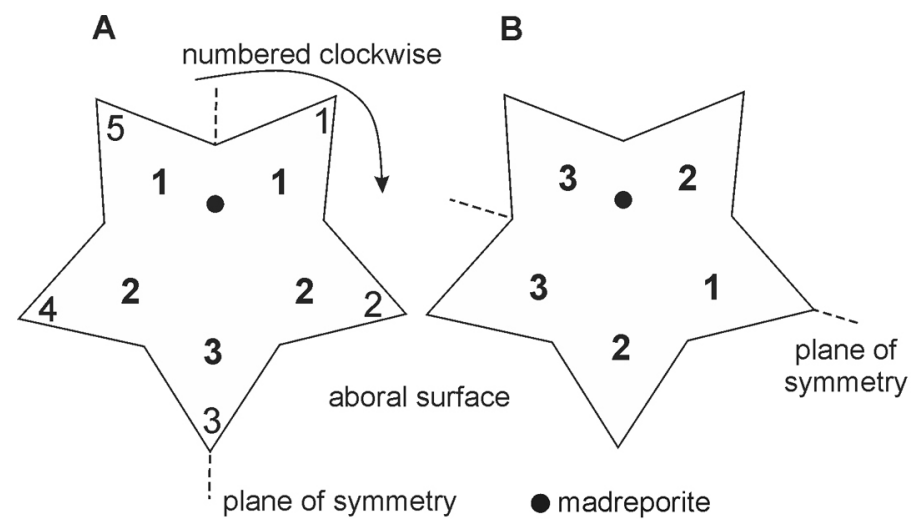

Fig. 2. Aboral view of the three arm-numbering systems used to describe the sea star's bilateral behavior. Arms numbered clockwise ( 1 to 5 ) from the madreporite. A. Arm numbering was assigned (numbers in bold) based on equivalent position across the madreporite plane of symmetry (according to Montgomery \& Palmer, 2012). B. Arm numbering according to equal reference across the plane of symmetry located from arm 2 to interradius 4-5 (according to Ji et al., 2012). 
symmetry defined the arm numbering (according to Montgomery \& Palmer, 2012) (Fig. 2A), and (3) the relative position of each ray across the plane of symmetry located from arm 2 to interradius 4-5 identified this arm numbering (according to Ji et al., 2012) (Fig. 2B). During both trials, sea stars' arms were identified (arm numbering system) and followed.

Data analysis: We used the Gaussian linear regressions, a Generalized Linear Model (GLM) to analyze the sea star crawling behavior in terms of average crawling speed (ACS), linearity (L), and the number of direction changes (DC) over a horizontal surface with and without water current, and on a vertical surface for sea stars going downwards or upwards. We calculated a Poisson GLM regression because DC is a count data (Zuur, Ieno, Walter, Saveliev, \& Smith, 2009). In the same way, we also analyzed the relation of ACS, L, and DC with sea star size (radius and wet weight). We used the post-hoc Least Squares Means pairwise comparisons to identify significant differences across groups.

We used Rayleigh's $z$-test for angular dispersion to test whether the orientation angles had a uniform distribution on the circle (an expected result when there is no influence on movement direction). The same test also verified a significant directional trend in the sea stars' movement due to the current water effect. Moreover, we used the Watson-Wiliams' $\mathrm{U}^{2}$-test for the mean angle formed by pairwise samples to analyze directionality differences between water flow conditions (Zar, 1999). Also, we performed the log-likelihood ratio test for goodness of fit (G-test; Zar, 1999) to compare the number of individuals that crawl upwards against downwards during vertical surface trials.

We carried out a log-likelihood ratio test for goodness of fit (G-test; Zar, 1999) to assess the existence of a bilateral plane of symmetry affecting locomotion and up-righting movements. Then, we compare the individuals' arm preference in up-righting and crawling according to the three arm-numbering systems.
We used the open-access Software R (R Core Team, 2019) for all statistical analyses as following: the emmeans package for pairwise comparisons (Russell, 2019), the circular package for the Rayleigh's $z$-test and WatsonWiliams' U²-test (Agostinelli \& Lund, 2017), and the script developed by Hurd (2001) for the G-test.

\section{RESULTS}

Sea star crawling behavior: The instantaneous crawling speeds presented an acceleration phase followed by an oscillating plateau.

The analyses indicated that ACS changes according to water flow conditions and locomotion plane (Table 1). In this sense, sea stars crawled faster when subject to water current than still water or a vertical surface; and speed was slower going upwards than downwards (Table 1, Table 2, Fig. 3). Moreover, there were no differences in the number of sea stars that crawl downwards or upwards (51 downwards, 69 upwards; G-value $=2.417, \mathrm{P}=0.120$ ).

Similarly, displacement linearity (L) over the horizontal surface presented significantly higher values in the presence of a water current. On the other hand, displacement linearity was similar in the absence of water current and when crawling on a vertical surface (Table 1, Table 2). However, there were no significant differences between going upwards or downwards (Table 1, Table 2, Fig. 3). Consequently, L's values suggest that sea stars' crawling behavior in the water current regime tended to be directional $(>0.7)$. In the absence of water flow and faced to the vertical surface, their behavior ranged from partially directional ( $>$ $0.5)$ to non-directional $(<0.5)$ (Fig. 3).

The number of direction changes (DC) during sea star locomotion differed between experimental treatments. In the presence of the current water regime, most individuals presented no differences in crawling direction. However, in the still water, some sea stars had the most remarkable direction changes during their locomotion (4 and 5 turns) (Table 1, Table 2, Fig. 4). On the other hand, when crawling over 
TABLE 1

Comparison of locomotion features related to sea star size, under two water regimes and surface inclination: using summary statistics (A) and Generalized Linear Model analyses (B) (N = 120/trial)

\begin{tabular}{|c|c|c|c|c|c|c|c|c|c|}
\hline $\begin{array}{l}\text { A) Summary } \\
\text { statistics }\end{array}$ & \multicolumn{3}{|c|}{ ACS } & \multicolumn{3}{|c|}{$\mathrm{L}$} & \multicolumn{3}{|c|}{$\mathrm{DC}$} \\
\hline Wc & \multicolumn{3}{|c|}{$4.55 \pm 1.06 \mathrm{~cm} / \mathrm{min}$} & \multicolumn{3}{|c|}{$0.83 \pm 0.11$} & \multicolumn{3}{|c|}{$1.18 \pm 1.22$} \\
\hline $\mathrm{Sw}$ & \multicolumn{3}{|c|}{$1.87 \pm 0.80 \mathrm{~cm} / \mathrm{min}$} & \multicolumn{3}{|c|}{$0.60 \pm 0.20$} & \multicolumn{3}{|c|}{$1.64 \pm 1.58$} \\
\hline Vs & \multicolumn{3}{|c|}{$1.82 \pm 0.99 \mathrm{~cm} / \mathrm{min}$} & \multicolumn{3}{|c|}{$0.62 \pm 0.20$} & \multicolumn{3}{|c|}{$1.08 \pm 1.14$} \\
\hline Up & \multicolumn{3}{|c|}{$1.26 \pm 0.54 \mathrm{~cm} / \mathrm{min}$} & \multicolumn{3}{|c|}{$0.63 \pm 0.21$} & \multicolumn{3}{|c|}{$1.67 \pm 1.15$} \\
\hline Down & \multicolumn{3}{|c|}{$2.59 \pm 0.98 \mathrm{~cm} / \mathrm{min}$} & \multicolumn{3}{|c|}{$0.61 \pm 0.19$} & \multicolumn{3}{|c|}{$0.29 \pm 0.46$} \\
\hline $\begin{array}{l}\text { B) Dependent } \\
\text { variables }\end{array}$ & d.f. & $\begin{array}{l}\text { Chi-square } \\
\text { value }\end{array}$ & $\mathrm{P}$ & d.f. & $\begin{array}{l}\text { Chi-square } \\
\text { value }\end{array}$ & $\mathrm{P}$ & d.f. & $\begin{array}{l}\text { Chi-square } \\
\text { value }\end{array}$ & $\mathrm{P}$ \\
\hline $\begin{array}{l}\mathrm{T} \\
(\mathrm{Wc}-\mathrm{Sw}-\mathrm{Vs})\end{array}$ & 2 & 581.29 & $<0.001$ & 2 & 182.61 & $<0.001$ & 2 & 118.69 & $<0.001$ \\
\hline $\mathrm{R}$ & 1 & 1.78 & 0.182 & 1 & 2.25 & 0.134 & 1 & 1.98 & 0.159 \\
\hline W & 1 & 1.20 & 0.273 & 1 & 1.40 & 0.237 & 1 & 1.85 & 0.174 \\
\hline ACS & - & - & - & - & - & - & 1 & 106.84 & $<0.001$ \\
\hline $\mathrm{L}$ & - & - & - & - & - & - & 1 & 16.23 & $<0.001$ \\
\hline $\begin{array}{l}\text { T } \\
\text { (Up-Down) }\end{array}$ & 1 & 75.04 & $<0.001$ & 1 & 0.29 & 0.589 & 1 & 45.85 & $<0.001$ \\
\hline $\mathrm{R}$ & 1 & 1.13 & 0.287 & 1 & 0.001 & 0.975 & 1 & 0.73 & 0.393 \\
\hline W & 1 & 1.42 & 0.234 & 1 & 0.39 & 0.534 & 1 & 0.11 & 0.739 \\
\hline ACS & - & - & - & - & - & - & 1 & 1.92 & 0.166 \\
\hline $\mathrm{L}$ & - & - & - & - & - & - & 1 & 0.36 & 0.546 \\
\hline
\end{tabular}

$\mathrm{ACS}=$ average crawling speed; $\mathrm{L}=$ linearity; $\mathrm{DC}=$ direction changes; $\mathrm{T}=$ treatment $\mathrm{Wc}=$ water current; $\mathrm{Sw}=$ still water; $\mathrm{Vs}=$ vertical surface; $\mathrm{R}=$ sea star radius; $\mathrm{W}=$ sea star weight.

TABLE 2

Post-hoc Least Squares Means pairwise comparisons of locomotion features between water current and surface inclination trials

\begin{tabular}{lccccccccc}
$\begin{array}{c}\text { Response } \\
\text { variable } \\
\text { comparisons }\end{array}$ & Dif \pm S.E. & t-value & P-value & Dif \pm S.E. & t-value & P-value & Dif \pm S.E. & z-value & P-value \\
Sw - Wc & $-2.675 \pm 0.120$ & -22.21 & $<0.001$ & $-0.227 \pm 0.021$ & -10.98 & $<0.001$ & $-1.808 \pm 0.204$ & -8.85 & $<0.001$ \\
Sw - Vs & $0.053 \pm 0.116$ & 0.46 & & $-0.017 \pm 0.026$ & -0.66 & 0.783 & $0.404 \pm 0.117$ & 3.47 & 0.002 \\
Wc - Vs & $2.727 \pm 0.132$ & 20.60 & $<0.001$ & $0.210 \pm 0.021$ & 10.06 & $<0.001$ & $2.212 \pm 0.216$ & 10.22 & $<0.001$ \\
Down - Up & $1.313 \pm 0.152$ & 8.66 & $<0.001$ & $-0.020 \pm 0.037$ & -0.54 & 0.590 & $-2.029 \pm 0.345$ & -5.88 & $<0.001$ \\
\hline
\end{tabular}

$\mathrm{ACS}=$ average crawling speed; $\mathrm{L}=$ linearity; $\mathrm{DC}=$ direction changes; $\mathrm{Wc}=$ water current; $\mathrm{Sw}=$ still water; Vs $=$ vertical surface; Dif = estimated difference between treatments.

a vertical surface, sea stars showed the slightest direction changes when moving downwards (Table 1, Table 2, Fig. 4).

Our results showed that there was no effect of body size (radius and wet weight) on the locomotion traits (ACS, L, and DC) of A. stellifera (Table 1).
On the other hand, the Rayleigh $z$-test showed that the orientation angle distribution was not significantly different from uniformity in all experimental crawling conditions (Fig. 5). Moreover, the orientation angles were not significantly different between treatments (Watson-Wiliams's $\mathrm{U}^{2}$-test: water current-still 

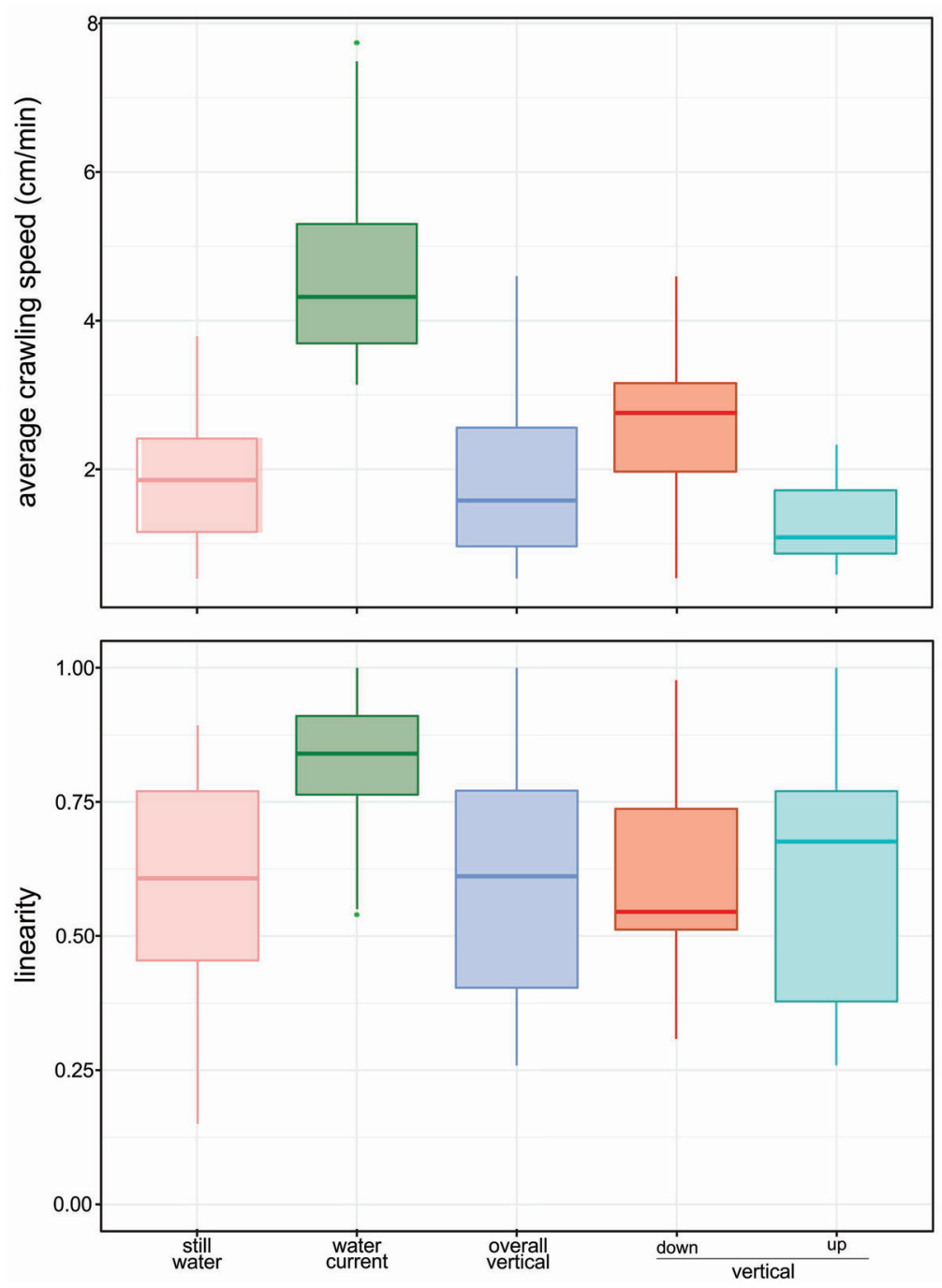

Fig. 3. Average crawling speed (cm/min) and linearity regarding two water-flow regimes (still water, pink; water current, green; $\mathrm{N}=120$ sea stars/trial) and the plane of substrata $\left(90^{\circ}\right.$ vertical plane, blue; $\mathrm{N}=120$ sea stars) going downwards (red) and upwards (aquamarine).

water, $\left.\mathrm{U}^{2}=0.056, \mathrm{P}>0.1\right)$. Therefore, sea stars did not exhibit a preferential angle of movement.

Sea star bilateral-like behavior: During crawling behavior trials, all sea stars moved with two leading arms forward, two on the side, and one backward. Sea stars used different pair combinations of leading arms while crawling. Arm preference during locomotion did not differ from random in any three-arm classes analyzed (Table 3 ).

During righting, sea stars first extended their arms upwards, attached two adjacent arms to the aquarium floor for support, and made the up-righting movement using the opposite arm. During the position-recovering, arm preference did not differ significantly from random in any of the three-arm classes analyzed (Table 3 ). Therefore, the up-righting and crawling 

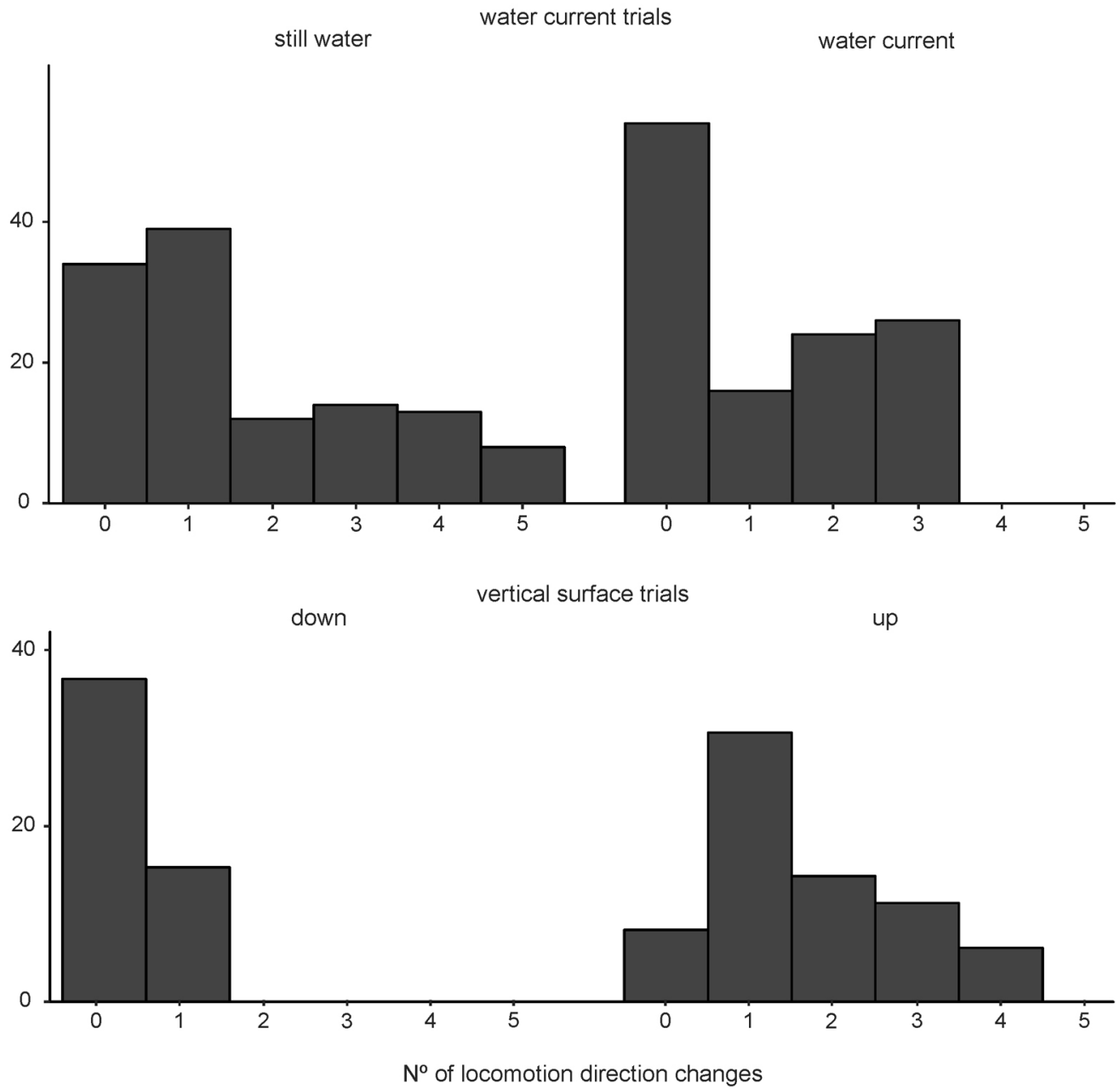

Fig. 4. The locomotion direction changes regarding the two water-flow regimes studied (still water and water current; $N=$ 120 sea stars/treatment) and vertical surface trials (going downwards and upwards; $\mathrm{N}=120$ sea stars).

TABLE 3

Bilateral-like movement trials: Arm preference during locomotion $(\mathrm{N}=120)$ and righting $(\mathrm{N}=100)$ trials

\begin{tabular}{|c|c|c|c|c|c|c|c|}
\hline \multirow{2}{*}{ Arm classes } & \multicolumn{5}{|c|}{ Arm numbering } & \multicolumn{2}{|c|}{ G-test } \\
\hline & 1 & 2 & 3 & 4 & 5 & G & $P$ \\
\hline \multicolumn{8}{|l|}{ Crawling Trials } \\
\hline arms individually numbered & 0.17 & 0.22 & 0.24 & 0.22 & 0.15 & 2.983 & 0.561 \\
\hline madreporite axis & 0.45 & 0.39 & 0.16 & - & - & 1.485 & 0.476 \\
\hline arm 2 to inter-radius $4-5$ axis & 0.27 & 0.39 & 0.34 & - & - & 3.180 & 0.204 \\
\hline \multicolumn{8}{|l|}{ Righting Trials } \\
\hline arms individually numbered & 0.23 & 0.20 & 0.24 & 0.15 & 0.18 & 2.757 & 0.599 \\
\hline madreporite axis & 0.41 & 0.35 & 0.24 & - & - & 1.429 & 0.489 \\
\hline arm 2 to inter-radius $4-5$ axis & 0.20 & 0.47 & 0.33 & - & - & 2.463 & 0.292 \\
\hline
\end{tabular}



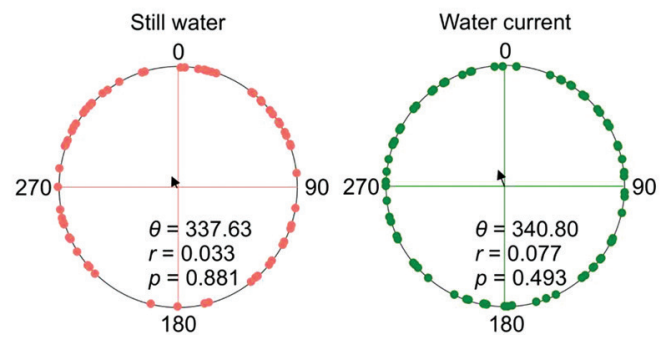

Fig. 5. Orientation in the presence and absence of water current. Dots represent the position of a sea star at the end of the trial. The current water direction is at $0^{\circ}$. Arrows represent the mean angular vector. The $\mathrm{P}$-values represent the Rayleigh $z$-test for angular dispersion (expected points uniformly distributed on the circle). $\theta$, mean orientation angle; $r$, mean vector length; $\mathrm{N}=120$ sea stars/treatment.

experiments show no symmetric behavioral plane of locomotion in A. stellifera.

\section{DISCUSSION}

Sea star crawling behavior: Describing sea star crawling movements can help to elucidate different ecological aspects related to individual foraging behavior, migration, and relationships among individuals within and among species. Since these behaviors involve a complex integration of body symmetry, sensory system, and other body characteristics, it is not striking that contradicting crawling actions could be described between and within echinoderms classes.

Crawling speed values recorded for $A$. stellifera are similar to those of other sea star species with comparable body sizes (40-70 $\mathrm{mm}$ ) living in temperate waters (Montgomery \& Palmer, 2012).

In general, animals present a positive relationship between body size and displacement speed. Mainly, echinoderms show different patterns in this relationship. However, considering that the efficiency of displacement depends on both the number of tube feet and body weight, it is expected that big sea stars move faster than the small ones (Ferlin, 1973; Mueller, Bos, Graf, \& Gumanao, 2011; Montgomery \& Palmer, 2012; Montgomery,
2014). In conclusion, a species-specific variability in the relationship between body size and movement speed in sea stars may occur. In accordance, our results show no association between crawling speed and radius nor wet weight for adult $A$. stellifera, regardless of the presence or absence of water current and plane of locomotion. There is a relationship between the ambulacral groove area (area on the oral surface containing tube feet) and the sea star's radius. (Mueller et al., 2011; Montgomery \& Palmer, 2012; Montgomery, 2014). These positive direct relationship between the radius and the ambulacral groove area might be more significant in bigger sea stars than in small or medium ones (Montgomery \& Palmer, 2012) such as A. stellifera. Thus, the absence of a relationship between $A$. stellifera's speed and size needs further investigation. A possible explanation may arise from the relationship between its ambulacral groove area and radius.

On the other hand, it is noteworthy that few studies have analyzed the crawling linearity variation. The available data regarding the foraging behavior of sea stars describe changes in that parameter concerning prey items (Moore \& Lepper, 1997; Drolet \& Himmelman, 2004; Thompson, Drolet, \& Himmelman, 2005; Barahona \& Navarrete, 2010; Montgomery \& Palmer, 2012). Although linearity is a descriptive dimensionless parameter, it provides information about crawling behaviors concerning trajectory shape or directional efficiency (Ricci, Barbanera, \& Erra, 1998). In this study, individuals traveled a relatively straight trajectory $(\mathrm{L}>0.7)$ on a horizontal surface and under the presence of a water current. We observed no $L$ values differences between individuals crawling on a flat surface with still water and a vertical surface, neither between $\mathrm{L}$ values and the sea star size. Thus, by crawling in a linear trajectory, A. stellifera would not be walking the same path twice, optimizing energy, e.g. avoiding sampling twice an area during foraging.

For many marine organisms, water currents trigger individuals' movement (rheotaxis) or help to detect prey cues (chemotaxis). In the 
latter case, it increases the chances of detecting chemical stimuli (Valentincic, 1983; Rochette et al., 1994; Mueller et al., 2011). Some studies reported evidence of chemoreception and positive rheotaxis for some sea stars species (McClintock \& Lawrence, 1981; Moore \& Lepper, 1997), but not in others (Sloan \& Campbell, 1982; Mueller et al., 2011). Asterina stellifera showed a random orientation behavior both in the presence and absence of water current regarding the crawling orientation angle and linearity on a horizontal surface. Moreover, the water current caused faster and straighter individual displacement, but not an oriented movement with or against the water current. In other words, A. stellifera did not show rheotaxis. As stated before, natural selection can optimize locomotion concerning prey distribution and abundance over evolutionary time (Pyke, Pulliam, \& Charnov, 1977). In this sense, a randomly oriented but linear movement may favor animals that belong to highly dense populations in communities with high prey density (McClintock \& Lawrence, 1981; Mueller et al., 2011). Asterina stellifera seems to be well-adapted to moving randomly in a dense community. This species' population reaches densities of up to $72 \mathrm{ind} / \mathrm{m}^{-2}$ and lives in a subtidal environment with abundant prey in the South Atlantic (Farias et al., 2012; Meretta et al., 2014). Future studies on the crawling behavior of sea stars in the presence of prey will help to understand the foraging strategy of this species.

Regarding the inclination of the surface of locomotion (i.e. bottom structure), our study showed that it affects this sea star's crawling behavior. The crawling speed of $A$. stellifera during trials was higher when the individuals moved downwards on a vertical plane than going upwards, probably due to the extra mechanical work associated with the gravitational force. However, there is no relationship between sea star size ( $\mathrm{R}$ and wet weight) and its vertical locomotion speed. According to Domenici, González-Calderón, and Ferrari (2003), sea stars adhere to the substrate to keep themselves in a vertical plane for much more time than they do to move downwards or on a horizontal bottom. Therefore, the gravitational force helps sea stars to move downwards faster.

Sea star bilateral behavior: During crawling behavior trials, all A. stellifera individuals moved with two leading arms forward, two on the side, and one backward, as reported for other sea star species (Reese, 1966; Ji et al., 2012). Similarly, during righting, sea stars first extended their arms upwards, attached two adjacent arms to the aquarium floor for support, and made the up-righting movement with the opposite arm, as reported for other sea star species (Polls \& Gonor, 1975). Therefore, the results obtained in this study are comparable to those.

Many studies analyze the bilateral behavior of echinoderms, with contradictory results. Most of them have focused on some regular echinoids and asteroids. Sea urchins appear to have no Anterior/Posterior axis of symmetry when crawling in an open space (Parker, 1936; Grabowsky, 1994; Yoshimura \& Motokawa, 2008, 2010; Yoshimura, Iketani, \& Motokawa, 2012). Similarly, Preyer (1887, as cited in Cole, 1913) conducted some experiments with ophiuroids (Ophiomyxa sp. and Ophioderma sp.) and found no preference for any particular ray during locomotion.

Regarding asteroids, some studies reported the existence of a behavioral $\mathrm{A} / \mathrm{P}$ axis or a tendency to have one during locomotion and righting in several species (Cole, 1913; Kjerschow-Agersborg, 1922; O’Donoghue, 1926; Polls \& Gonor, 1975; Ji et al., 2012; ArdorBellucci \& Smith, 2019). However, other sea stars did not exhibit an A/P plane of symmetry during crawling nor righting (Preyer, 1887, as cited in Cole, 1913; Ohshima, 1940; Montgomery \& Palmer, 2012). Furthermore, it is still unclear why some species use one combination of arms more frequently than the others as leading arms (Polls \& Gonor, 1975; Ji et al., 2012; Ardor-Bellucci \& Smith, 2019). And also, why other species do not follow any pattern (Ohshima, 1940; Polls \& Gonor, 1975; Montgomery \& Palmer, 2012; this study). In 
this sense, the potential existence of a tendency toward bilateral behavior may be a speciesspecific characteristic rather than a generalized feature of all echinoderms.

Asterina stellifera is another example of a species that did not exhibit an A/P plane of symmetry during crawling nor righting. As is evidenced in the literature, there is a considerable time lag in investigations on this subject. The methodology associated with experimentation and data analysis has changed. Thus, these results contribute as an example to the discussion regarding a functional bilateral axis in adult asteroids and update the subject.

In all asteroids, the water vascular system and the nervous system assume a pentaradial symmetry. Radial distribution of sense organs allows sea stars to perceive their surrounding environment continuously from all directions and move towards or away from a stimulus (prey or enemy). Understanding the mechanisms by which sea stars detect and respond to different stimuli will help elucidate ecological aspects such as prey detection and selection, avoid predators, and respond to changes in environmental conditions.

In conclusion, our results show that (1) $A$. stellifera presents no rheotaxis, but gravitaxis, (2) locomotion speed and linearity are independent of body size, and (3) this species would not tend to bilateral behavior.

Ethical statement: authors declare that they all agree with this publication and made significant contributions; that there is no conflict of interest of any kind; and that we followed all pertinent ethical and legal procedures and requirements. All financial sources are fully and clearly stated in the acknowledgements section. A signed document has been filed in the journal archives.

\section{ACKNOWLEDGMENTS}

We are grateful to Mar del Plata Aquarium for allowing us to use their facilities for aquariums experimentation with their flow through seawater system. During the experimentation period, PEM was supported by a Ph.D. Fellowship funded by CONICET - Consejo Nacional de Investigaciones Científicas y Técnicas. CRRV is supported by Research Fellowships of the Conselho Nacional de Desenvolvimento Científico e Tecnológico (CNPq) and the Fundação Carlos Chagas de Amparo à Pesquisa do Estado do Rio de Janeiro (FAPERJ).

\section{RESUMEN}

\section{Comportamiento de locomoción y enderezamiento en estrellas de mar: un caso de estudio sobre la estrella Asterina stellifera (Asterinidae)}

Introducción: El comportamiento de locomoción de un organismo implica la integración de aspectos como la simetría corporal, los sistemas sensorial y locomotor. Además, varios factores ecológicos parecen estar relacionados con las características de la locomoción, como la estrategia de alimentación, las tendencias migratorias, la respuesta a los depredadores y competidores y el estrés ambiental. Objetivo: Analizar el patrón general de locomoción y la influencia de la simetría corporal en la locomoción y enderezamiento de la estrella de mar Asterina stellifera. Métodos: Realizamos experimentos de laboratorio en acuarios en presencia / ausencia de corriente de agua y en superficie horizontal y vertical. Resultados: La velocidad es similar a la velocidad en otras especies de tamaño similar. Tanto la velocidad como la linealidad del desplazamiento fueron independientes del tamaño corporal individual. Una corriente de agua conduce a una velocidad de desplazamiento mayor y a trayectorias más rectas, pero no hay reotaxis: una corriente de agua no afecta el patrón de locomoción. La velocidad y la linealidad del desplazamiento fueron independientes del tamaño corporal individual. El patrón de desplazamiento aquí descrito puede ser una adaptación de organismos que presentan densas poblaciones en comunidades con alta abundancia de presas, como es el caso de $A$. stellifera. Conclusiones: Al igual que otros asteroides, esta especie no mostró un plano de simetría Anterior / Posterior durante la locomoción o el movimiento de enderezamiento: no tiende a la bilateralidad.

Palabras clave: locomoción; orientación; bilateralidad; Asteroidea; reotaxis; gravitaxis

\section{REFERENCES}

Agostinelli, C., \& Lund, U. (2017). R package “circular": Circular Statistics (version 0.4-93). Retrieved from https://r-forge.r-project.org/projects/circular/

Ardor-Bellucci, L.M., \& Smith, N.F. (2019). Crawling and righting behavior of the subtropical sea star 
Echinaster (Othilia) graminicola: effects of elevated temperature. Marine Biology, 166, 138.

Barahona, M., \& Navarrete, S.A. (2010). Movement patterns of the seastar Heliaster helianthus in central Chile: relationship with environmental conditions and prey availability. Marine Biology, 157, 647-661.

Castilla, J.C. (1972). Avoidance behavior of Asterius rubens to extracts of Mytilus edulis, solutions of bacteriological peptone, and selected amino acids. Marine Biology, 15, 236-245.

Cole, L.J. (1913). Direction of locomotion of the starfish (Asterias forbesi). Journal of Experimental Zoology, 14,1-32.

Dale, J. (1997). Chemosensory search behavior in the starfish Asterias forbesi. The Biological Bulletin, 193(2), 210.

Dale, J. (1999). Coordination of chemosensory orientation in the starfish Asterias forbesi. Marine and Freshwater Behaviour and Physiology, 32, 57-71.

Domenici, P., González-Calderón, D., \& Ferrari, R.S. (2003). Locomotor performance in the sea urchin Paracentrotus lividus. Journal of the Marine Biological Association of the United Kingdom, 83(2), 285-292.

Drolet, D., \& Himmelman, J.H. (2004). Role of current and prey odour in the displacement behaviour of the sea star Asterias vulgaris. Canadian Journal of Zoology, 82(10), 1547-1553.

Dusenbery, D.B. (1992). Sensory Ecology: How organisms acquire and respond to information. New York: W.H. Freeman.

Farias, N.E., Meretta, P.E., \& Cledón, M. (2012). Population structure and feeding ecology of the bat star Asterina stellifera (Möbius, 1859): Omnivory on subtidal rocky bottoms of temperate seas. Journal of Sea Research, 70, 14-22.

Feder, H.M., \& Christensen, A.M. (1966). Aspects of asteroid biology. In R. Boolotian (Ed.), Physiology of Echinodermata (pp. 87-127). New York: Wiley.

Ferlin, V. (1973). The mode of dislocation of Astropecten aranciacus. Helgoland Marine Research, 24, 151-156.

Gaymer, C.F., \& Himmelman, J.H. (2008). A keystone predatory sea star in the intertidal zone is controlled by a higher-order predatory sea star in the subtidal zone. Marine Ecology Progress Series, 370, 143-153.

Genzano, G., Giberto, D., \& Bremec, C. (2011). Benthic survey of natural and artificial reefs off Mar del Plata, Argentina, southwestern Atlantic. Latin American Journal of Aquatic Research, 39(3), 553-566.
Grabowsky, G.L. (1994). Symmetry, locomotion, and the evolution of an anterior end: a lesson from sea urchins. Evolution, 48(4), 1130-1146.

Hurd, P. (2001). Log-likelihood tests of independence and goodness of fit. Retrieved from http://www.pmc.ucsc. edu/ mclapham/Rtips/G\%20test.txt

Ji, C., Wu, L., Zhao, W., Wang, S., \& Lv, J. (2012). Echinoderms have bilateral tendencies. PLOS ONE, 7, 1-6.

Kjerschow-Agersborg, H.P. (1922). The relation of the madreporite to the physiological anterior end in the twenty-rayed starfish, Pycnopodia helianthoides (Stimpson). Biological Bulletin, 42(4), 202-216.

McClintock, J.B., \& Lawrence, J.M. (1981). An optimization study on the feeding behavior of Luidia clathrata say (Echinodermata: Asteroidea). Marine Behaviour \& Physiology, 7, 263-275.

McClintock, J.B., \& Lawrence, J.M. (1984). Ingestive conditioning in Luidia clathrata (Say) (Echinodermata: Asteroidea): Effect of nutritional condition on selectivity, teloreception, and rates of ingestion. Marine Behavior and Physiology, 10, 167-181.

Meretta, P.E., Farias, N.E., Cledón, M., \& Ventura, C.R. (2016). Growth pattern and changes in abundance of the endangered bat star Asterina stellifera. Marine Ecology, 37, 1423-1433.

Meretta, P.E., Rubilar, T., Cledón, M., \& Ventura, C.R.R. (2014). Geographical implications of seasonal reproduction in the bat star Asterina stellifera. Journal of Sea Research, 85, 222-232.

Montgomery, E.M., \& Palmer, A.R. (2012). Effects of body size and shape on locomotion in the bat star (Patiria miniata). Biological Bulletin, 222, 222-232.

Montgomery, E.M. (2014). Predicting crawling speed relative to mass in sea stars. Journal of Experimental Marine Biology and Ecology, 458, 27-33.

Moore, P.A., \& Lepper, D.M.E. (1997). Role of chemical signals in the orientation behavior of the sea star Asterias forbesi. Biological Bulletin, 192(3), 410-417.

Mueller, B., Bos, A.R., Graf, G., \& Gumanao, G.S. (2011). Size-specific locomotion rate and movement pattern of four common Indo-Pacific sea stars (Echinodermata; Asteroidea). Aquatic Biology, 12, 157-164.

O'Donoghue, C.H. (1926). On the summer migration of certain starfish in Departure Bay. Journal of the Fisheries Research Board of Canada, 1(3), 455-472.

Ohshima, H. (1940). The righting movement of the seastar, Oreaster nodosus (L.). Japanese Journal of Zoology, 8, 575-589.

Parker, G.H. (1936). Direction and means of locomotion in the regular sea-urchin Lytechinus. Mémoires $d u$ Musée Royal d'histoire Naturelle de Belgique Series, 3, 197-208. 
Polls, I., \& Gonor, J. (1975). Behavioral aspects of righting in two asteroids from the Pacific coast of North America. Biological Bulletin, 148(1), 68-84.

Preyer, W.T. (1887). Die Bewegungen der Seesterne. Mittheilungen aus der Zoologischen Station zu Neapel, 7, 191-233.

Pyke, G.H., Pulliam, H.R., \& Charnov, E.L. (1977). Optimal foraging: a selective review of theory and tests. The Quarterly Review of Biology, 52(2), 137-154.

R Core Team. (2019). R: A language and environment for statistical computing. R Foundation for Statistical Computing, Vienna, Austria. Retrieved from http:// www.R-project.org/

Reese, E.S. (1966). The complex behaviour of echinoderms. In R.A. Boolootian (Ed.), Physiology of Echinodermata (pp. 157-218). New York: Interscience Publishers.

Ricci, N., Barbanera, F., \& Erra, F. (1998). A quantitative approach to movement, displacement, and mobility of protozoa. Journal of Eukaryotic Microbiology, $45,606-611$.

Rochette, R., Hamel, J.F., \& Himmelman, J.H. (1994). Foraging strategy of the asteroid Leptasterias polaris: role of prey odors, current and feeding status. Marine Ecology Progress Series, 106, 93-100.

Russell, L. (2019). emmeans: Estimated Marginal Means, aka Least-Squares Means. R package version 1.4. Retrieved from https://CRAN.R-project.org/ package $=$ emmeans

Scheibling, R.E. (1981). Optimal foraging movements of Oreaster reticulatus (L.) (Echinodermata: Asteroidea). Journal of Experimental Marine Biology and Ecology, 51(2-3), 173-185.

Sloan, N.A. (1979). Starfish encounters: An experimental study of its advantages. Experientia, 35, 1314-1315.

Sloan, N.A. (1980). The arm curling and terminal tube foot responses of the asteroid Crossaster papposus (L.). Journal of Natural History, 14, 469-482.

Sloan, N.A., \& Campbell, A.C. (1982). Perception of food In M. Jangoux \& J.M. Lawrence (Eds.), Echinoderm nutrition (pp. 3-23). Rotterdam: A.A. Balkema.
Sloan, N.A., \& Northway, S.M. (1982). Chemoreception by the asteroid Crossaster papposus (L.). Journal of Experimental Marine Biology and Ecology, 61, 85-98.

Swenson, D.P., \& McClintock, J.B. (1998). A quantitative assessment of chemically-mediated rheotaxis in the asteroid Coscinasterias tenuispina. Marine \& Freshwater Behaviour \& Physiology, 31(2), 63-80.

Thompson, M., Drolet, D., \& Himmelman, J.H. (2005). Localization of infaunal prey by the sea star Leptasterias polaris. Marine Biology, 146, 887-894.

Valentincic, T. (1983). Innate and learned responses to external stimuli in asteroids. Echinoderm Studies, 1, 111-138.

Valentincic, T. (1985). Behavioral study of chemoreception in the sea star Marthasterias glacialis: Structureactivity relationships of lactic acid, amino acids, and acethylcholine. Journal of Comparative Physiology A, 157, 537-545.

Wyeth, R.C., Woodward, O.M., \& Dennis-Willows, A.O. (2006). Orientation and navigation relative to water flow, prey, conspecifics, and predators by the nudibranch mollusc Tritonia diomedea. Biological Bulletin, 210(2), 97-108.

Yoshimura, K., \& Motokawa, T. (2008). Bilateral symmetry and locomotion: do elliptical regular sea urchins proceed along their longer body axis?. Marine Biology, 154, 911-918.

Yoshimura, K., \& Motokawa, T. (2010). Bilaterality in the regular sea urchin Anthocidaris crassispina is related to efficient defense not to efficient locomotion. Marine Biology, 157, 2475-2488.

Yoshimura, K., Iketani, T., \& Motokawa, T. (2012). Do regular sea urchins show preference in which part of the body they orient forward in their walk?. Marine Biology, 159, 959-965.

Zar, J.H. (1999). Biostatistical analysis. New Jersey: Prentince Hall.

Zuur, A., Ieno, E.N., Walter, N.J., Saveliev, A.A., \& Smith, A.A. (2009). Mixed Effects Models and Extensions in Ecology with R. New York: Springer. 